\title{
DOENÇA RESPIRATÓRIA EM BOVINOS CONFINADOS
}

\author{
BOVINE RESPIRATORY DISEASE IN FEEDLOT
}

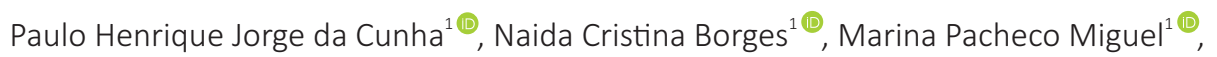

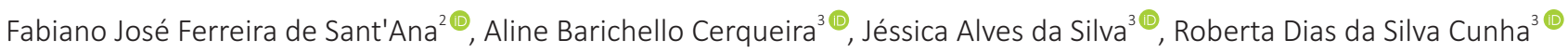

- 90.90

Escola de Veterinária e Zootecnia (EVZ) da Universidade Federal de Goiás (UFG), Goiânia, Goiás, Brasil.

Laboratório de Diagnóstico Patológico Veterinário (LDPV), Universidade de Brasília (UnB), Brasília, Distrito Federal, Brasil.

Programa de Pós-Graduação em Ciência Animal, Escola de Veterinária e Zootecnia (EVZ), Universidade Federal de Goiás (UFG), Goiânia, Goiás, Brasil.

Autor para correspondência: phcunha@ufg.br

Revista Brasileira de Buiatria Clínica Médica, Volume 1, Número 9, 2021

ISSN 2763-955X

DOI:10.4322/2763-955X.2021.009

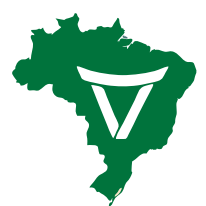

Associação Brasileira de Buiatria

\section{RESUMO}

A Doença Respiratória Bovina (DRB) é uma enfermidade de grande importância econômica em confinamentos de bovinos de corte devido à alta prevalência, baixo desempenho e morte dos animais acometidos. O objetivo deste artigo é apresentar uma revisão abordando os aspectos econômicos, epidemiológicos, estratégias de diagnóstico, tratamento e prevenção da DRB em bovinos confinados. Diferentes interações de fatores, como associação de microrganismos patogênicos, condições ambientais estressantes e animais imunologicamente susceptíveis, desafiam as estratégias de diagnóstico, tratamento e prevenção da DRB. Para minimizar os impactos, destaca-se a importância de se identificar a enfermidade em sua fase inicial. Os elevados índices de morbidade e mortalidade da DRB estimulam o estabelecimento de estratégias para o controle da doença. Os protocolos mais utilizados estão relacionados à metafilaxia ou a administração de vacinas. Não existe confinamento que atinja o sucesso, com boa produtividade, se não priorizar a sanidade do rebanho.

Palavras-chave: diagnóstico, gado corte, metafilaxia, pneumonia, prevenção, tratamento.

\section{ABSTRACT}

Bovine Respiratory Disease (BRD) is a disease of great economic importance in beef cattle feedlots due to its high prevalence, low performance, and death of the affected animals. The purpose of this article is to present a review addressing the economic, epidemiological aspects, diagnostic strategies, treatment, and prevention of BRD infeedlot cattle. Different interactions of factors such as the association of pathogenic microorganisms, stressful environmental conditions and immunologically susceptible animals challenge the diagnosis, treatment, and prevention of DRB. To minimize the impacts, it is important to identify the respiratory disease in initial stage. The high rates of morbidity and mortality in BRD stimulate the establishment of strategies to control the disease. The most widely used protocols are related to metaphylaxis or vaccine administration. There is no beef cattle feedlot that achieves success, with good productivity, if the health of the herd is not prioritized.

Keywords: beef cattle, diagnosis, metaphylaxis, pneumonia, prevention, treatment. 


\section{INTRODUÇÃO}

O confinamento é um sistema produtivo que vem crescendo constantemente no Brasil, atingindo o marco de aproximadamente seis milhões de bovinos. Em 2020, o número de cabeças confinadas no país registrou crescimento de 6\% sobre 2019 e, na região Centro-Oeste, que concentra o maior rebanho de bovinos confinados (2,89 milhões), a alta foi de $8 \%{ }^{1}$.

De acordo com dados publicados pela Scot Consultoria em $2021^{2}$, as médias dos indicadores zootécnicos declarados pelos confinadores foram: 21,6 meses de idade na entrada do confinamento; 108 dias de período de confinamento; $1,547 \mathrm{~kg} / \mathrm{cabeça/dia} \mathrm{de}$ ganho diário; 10,8 $\mathrm{kg}$ MS/cabeça/dia de consumo de matéria seca e 55,6\% de rendimento de carcaça.

Esse cenário promissor tem estimulado a indústria da carne e proporcionado melhorias na rentabilidade do negócio. A valorização da arroba e a tendência de mercado firme têm impulsionado a construção e/ou expansão dos confinamentos ${ }^{3}$. Entretanto, com o aumento na implantação de grandes confinamentos no país, focados principalmente na terminação de animais cada vez mais jovens, os problemas sanitários tendem a apresentar maior ocorrência ${ }^{4,5}$.

No confinamento de bovinos, as prevalências de doenças são influenciadas pelo estado imunológico, estresse, carga de patógenos, meio ambiente e fatores nutricionais. A Doença Respiratória Bovina (DRB) é a principal enfermidade que acomete os bovinos confinados nos Estados Unidos da América (EUA) ${ }^{6,7}$, Austrália $^{8}$, Canadá ${ }^{9}$ e Brasil ${ }^{10,11}$.

Os bovinos são frequentemente expostos a vários agentes patogênicos virais e bacterianos, ressalte-se que, muitos desses microrganismos envolvidos na manifestação da DRB são habitantes normais do trato respiratório superior ${ }^{12}$. Além disso, em função da virulência do agente e da suscetibilidade do hospedeiro, a DRB ocorre inicialmente por meio de uma infecção viral primária do aparelho respiratório superior, que predispõe a infecções bacterianas secundárias ${ }^{13}$.

Situações de estresse, que culminam na queda imunológica do bovino, ocasionam uma síndrome multifatorial complexa conhecida por "febre dos transportes" $^{\$ 14}$. Os índices de mortalidade e morbidade ${ }^{5}$, exames clínicos e laboratoriais, necropsias ${ }^{4,11}$ e o acompanhamento de abates no frigorífico são ferramentas úteis para o monitoramento da saúde dos bovinos confina$\operatorname{dos}^{15}$. Esses procedimentos possibilitam a coleta de amostras e a realização de exames de diagnóstico ante mortem e post mortem ${ }^{13}$.

O diagnóstico, tratamento, prevenção e o controle da DRB constituem um desafio devido à interação dos fatores de risco associados com ambiente, hospedeiro e agentes etiológicos. Para minimizar os impactos, destaca-se a importância de se identificar a DRB em sua fase inicial ${ }^{16}$. O objetivo deste artigo é apresentar uma revisão abordando os aspectos econômicos, epidemiológicos, estratégias de diagnóstico, tratamento e prevenção da DRB em bovinos confinados.

\section{IMPORTÂNCIA ECONÔMICA DA DOENÇA RESPIRATÓRIA BOVINA NOS CONFINAMENTOS}

Baptista et al. ${ }^{11}$ realizaram uma estimativa dos impactos econômicos associados à morbidade e mortalidade relacionada à DRB. Os custos operacionais incluíram todas as despesas associadas à alimentação e manutenção de cada animal por dia no confinamento. Os custos associados à vacinação e terapia foram estimados por animal em US\$1,22 e US\$ 4,00, respectivamente. $\mathrm{O}$ custo operacional médio relacionado à mortalidade foi de U\$118,29, o qual foi consideravelmente mais elevado em relação aos US $\$ 21,40$ associados à manutenção de um animal doente. Adicionalmente, a perda estimada associada à mortalidade por DRB foi de US\$588,86/animal. 


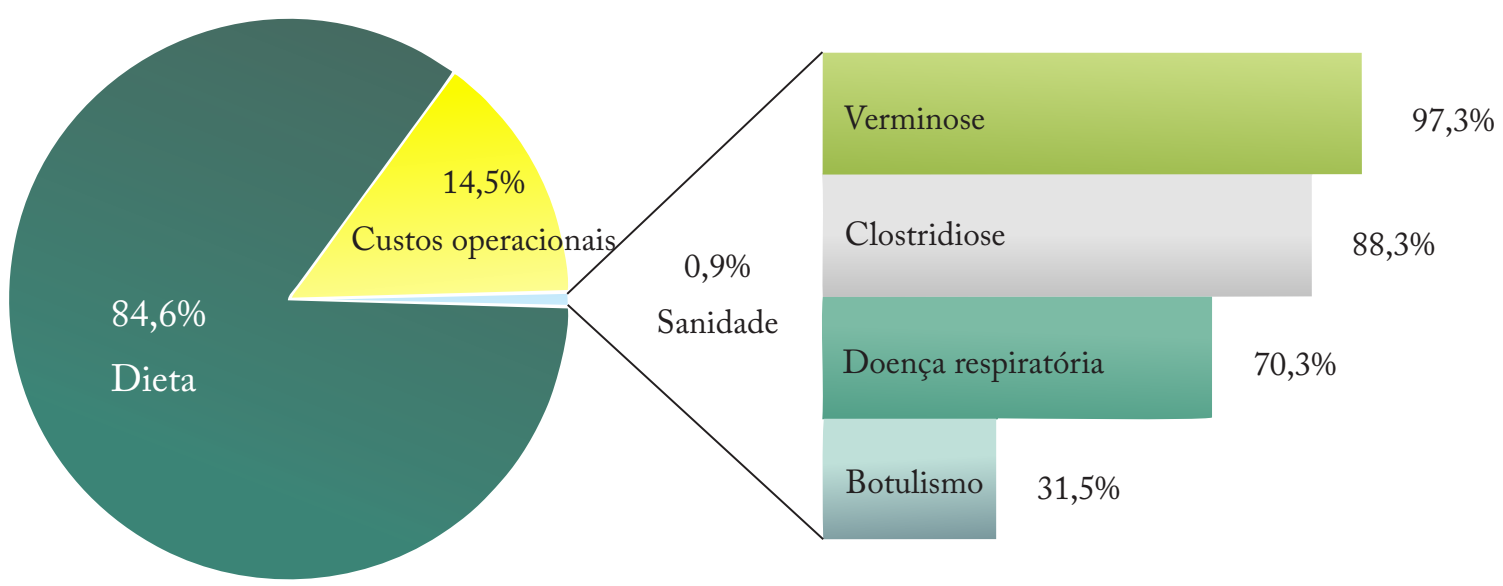

Figura 1: Porcentagem de custos e medidas preventivas sanitárias adotadas em bovinos de confinamento².

A DRB causa perdas econômicas significativas nos confinamentos devido à diminuição da produção e aumento dos custos associados ao tratamento. Blakebrough-Hall et al. ${ }^{17}$ relataram que, animais tratados com frequência igual ou superior a três vezes para DRB tiveram carcaças mais leves no abate, com perda de 39,6 kg. Bovinos com lesões pulmonares graves apresentaram redução de 14,3 kg de peso de carcaça e animais com DRB subclínico e clínico tiveram $16 \mathrm{~kg}$ e $24,1 \mathrm{~kg}$ de carcaças mais leves, respectivamente. Os animais que reduziram o desempenho, tiveram carcaças mais leves e pior retorno econômico devido ao número de tratamentos realizados e intensidade das lesões pulmonares e pleurais. Dessa forma, o monitoramento da intensidade das lesões pulmonares no abate constitui uma estratégia que visa reduzir os impactos da DRB nos confinamentos, pois permite identificar animais com doença subclínica e analisar os protocolos de tratamento.

A gestão sanitária com base em índices de mortalidade e morbidade tem auxiliado no estabelecimento do custo sanitário nos confinamentos. Dados da Foco Consultoria indicaram que no rebanho total de 606.178 bovinos confinados, 31.371 foram medicados $(5,18 \%)$ com custo sanitário médio de $\mathrm{R} \$$ 32,81/cabeça. Os animais doentes, medicados e abatidos em 2020 tiveram desempenho inferior a 18\% em relação aos sem enfermidade diagnosticada ${ }^{5}$.

Analisando os custos de confinamento, a Scot Consultoria ${ }^{2}$ estabeleceu um custo médio de $\mathrm{R} \$$ 1.044,98/cabeça, levando-se em conta um confinamento de 108 dias. Ao fracionar esse custo, a dieta representou $84,6 \%$ do custo total, $14,5 \%$ foram referentes à custos operacionais e 0,9\% são destinados à sanidade. As maiores preocupações e medidas preventivas em relação à sanidade foram: aplicação de vermífugos $(97,3 \%)$, prevenção de clostridioses $(88,3 \%)$, de doenças respiratórias (70,3\%) e de botulismo (31,5\%) (Figura 1). O custo com sanidade variou com o protocolo sanitário adotado e apresentou uma média de $\mathrm{R} \$$ 8,81 por animal confinado.

\section{EPIDEMIOLOGIA E ETIOPATOGENIA}

A frequência de morbidade e mortalidade de bovinos de corte confinados é uma ferramenta importante para monitorar o "status" sanitário. As causas de morte em confinamento variam em função do desafio encontrado na região na qual o mesmo é instalado. Em um confinamento no nordeste do estado de Minas Gerais, a taxa de morbidade foi de 7,05\%, e a mortalidade foi estimada em $0,64 \%$. A maioria $(86,9 \%)$ dos bovinos doentes desenvolveram DRB, sendo esta, a 
principal causa de morbidade $(6,13 \%)$ e de mortalidade $(0,21 \%)^{11}$.

Confinamentos que adquirem animais de terceiros apresentam incidência de pneumonia maior em comparação àqueles que trabalham apenas com gado próprio. Outro fator de risco que aumenta a suscetibilidade é a faixa etária e peso de entrada no confinamento. Animais mais leves são usualmente mais jovens e imaturos quando comparados a animais pesados, e demonstram menos oportunidades de contato com os patógenos, o que resulta em menor imunidade ${ }^{6}$. Dados nacionais indicaram que, o grupo mais suscetível a adoecer são os bezerros com menos de $210 \mathrm{~kg}$, que apresentaram 5,37\% de morbidade, taxa 53\% superior à média geral do estudo, que foi de 3,51\%. O número de animais doentes caiu conforme aumentava o peso, e a morbidade somente voltou a subir $(3,61 \%)$ nos animais com mais de $390 \mathrm{~kg}$. Desta maneira, os indicadores associados às metas, auxiliam os confinamentos a reduzir o percentual de animais mortos ou doentes, economizando com medicamentos e aumentando o lucro 5 .

Os principais patógenos virais que acometem bovinos confinados são Herpesvírus Bovino tipo 1 (BoHV-1), Vírus Sincicial Respiratório Bovino (VSRB), Coronavírus (BCov), Parainfluenza Bovino tipo 3 (BPI-3V) e Vírus da Diarreia Viral Bovina (BVDV). As bactérias oportunistas mais comumente relacionadas à DRB são a Mannheimia haemolytica, Pasteurella multocida, Histophilus somni e Mycoplasma bovis ${ }^{18}$.

Headley et al. ${ }^{19}$ identificaram associações simples e mistas de $H$. somni com Alfaherpesvirus-1 Bovino em bovinos confinados com DRB do norte do Paraná, e coinfecções de $H$. somni com VSRB em um confinamento do estado de São Paulo ${ }^{18}$. Baptista et al. ${ }^{11}$ detectaram no pulmão de novilhos com broncopneumonia, infecções bacterianas concomitantes devido à M. haemolytica e P. multocida.

De acordo com Wolfger et al. ${ }^{20}$, a suscetibili- dade à DRB é multifatorial, influenciada por uma interação complexa entre estresse, fatores ambientais e genéticos, múltiplos patógenos virais e bacterianos e a resposta imune do hospedeiro. Na infecção viral primária das células epiteliais da cavidade nasal, faringe, traqueia, brônquios e bronquíolos há perda de cílios e/ou necrose dessas células. Com a redução da limpeza mucociliar, acumulam-se fluidos e restos celulares nas vias aéreas e alvéolos, proporcionando ambiente ideal para a colonização bacteriana secundária ${ }^{21,22}$. Todos os fatores, isolados ou em conjunto proporcionaram maior comprometimento da resposta imune desses animais ${ }^{11,23,24}$.

Amplitudes térmicas elevadas associadas com baixa umidade (período seco) favorecem maior retenção de partículas de poeira no ar, aumentando a prevalência das DRB nos confinamentos ${ }^{11,25,26}$. Fatores de risco como transporte por longas distâncias (ruídos, vibrações, aglomeração, contenção, embarque e desembarque, tempo de trânsito, privação hídrica e alimentar), adaptação de ambientes, aglomeração de animais, mudanças de temperatura, desidratação, ambientes com poeira/barro, mistura de bovinos de múltiplas origens e introdução de uma nova alimentação contribuem para ocorrência da $\mathrm{DRB}^{27}$. Adaptação a novas dietas e mistura de bovinos de diferentes procedências também alteram a estrutura da microbiota nasofaríngea ${ }^{28,29}$.

A microbiota respiratória dos bovinos é dinâmica e sua composição está associada à saúde respiratória, mudando significativamente durante os episódios de DRB. O trato respiratório dos bovinos é habitado predominantemente por cinco filos (Proteobacteria, Firmicutes, Tenericutes, Actinobactérias e Bacteroidetes) e essa diversidade ocorre devido às propriedades biofísicas das superfícies da mucosa respiratória, isto é, temperatura, umidade e $\mathrm{pH}$. A composição, diversidade e estabilidade da microbiota respiratória podem desempenhar um papel tanto na predisposição do bovino a DRB ou fornecendo proteção contra a colonização e/ou proliferação de patógenos bacterianos no trato respiratório ${ }^{30}$. 
Holman et al..$^{27}$ compararam a microbiota do trato respiratório de bezerros saudáveis com aqueles que desenvolveram DRB e verificaram a presença de bactérias comensais específicas no trato respiratório, que conferem proteção contra a enfermidade. Além disso, animais com maior proporção de Lactobacillaceae e Bacillaceae em sua nasofaringe na entrada do confinamento apresentaram menor probabilidade de desenvolver DRB durante os primeiros 60 dias de alimentação.

Sabe-se que, as bactérias comensais podem conferir resistência contra a colonização e proliferação de patógenos bacterianos oportunistas por meio de diversos mecanismos. Primeiro, a resistência pode ser fornecida por meio da ocupação de um nicho respiratório vazio. Como resultado, os patógenos invasores precisam competir por receptores de adesão e nutrientes ${ }^{31}$. Bactérias comensais na nasofaringe também podem inibir diretamente o crescimento de patógenos bacterianos, modificando seu ambiente (produção de ácido láctico ou acético) ou produção de moléculas antimicrobianas (bacteriocinas e peróxido de hidrogênio $)^{32}$. Além disso, os comensais podem aumentar a resistência à colonização contra patógenos via estimulação imune do hospedeiro e modulação de inflamação da mucosa ${ }^{33}$.

\section{DIAGNÓSTICO CLÍNICO}

A morbidade por DRB nos confinamentos é predominante durante os primeiros 15 dias de alimentação ${ }^{11,34-37}$.

Nos confinamentos, a identificação de DRB é realizada por meio da utilização do sistema DART, ou seja, a inspeção baseada em indicadores visuais de depressão (D), perda de apetite (A), mudanças de padrão respiratório $(\mathrm{R})$ e elevação da temperatura $(\mathrm{T})^{38}$. O referido sistema é usado porque não necessita de equipamentos ou ferramentas de alto custo ${ }^{39}$. Entretanto, o emprego desse sistema apresenta baixa sensibilidade e especificidade ${ }^{40}$. Outro fator complicador é que, os bovinos instintivamente mascaram os sinais clínicos da doença, como meio de autopreservação ${ }^{13}$, podendo esconder seu verdadeiro estado de saúde, piorando o quadro clínico e o prognóstico ${ }^{41}$.

$\mathrm{Na} \mathrm{DRB}$, os sinais clínicos são variáveis, de quase imperceptíveis e brandos, na doença subclínica, até casos graves, na doença clínica hiperaguda, a qual pode levar à morte quando há pneumonia bacteriana secundária. Os sinais podem incluir apatia, anorexia, queda na produção, descarga nasal e ocular catarral, ptialismo, febre (acima de $40^{\circ} \mathrm{C}$ ), aumento da frequência respiratória e tosse ${ }^{42-44}$. Conforme a doença progride, os sinais tornam-se mais graves e incluem dispneia,

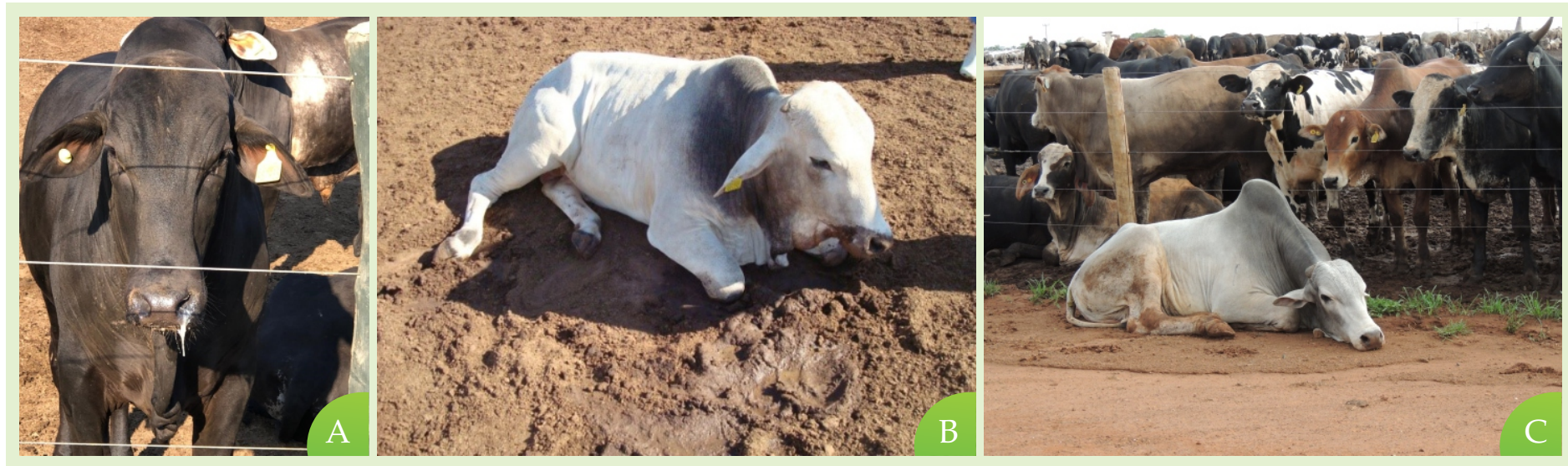

Figura 2. Evoluções clínicas de bovinos com doença respiratória no confinamento. (A) Secreção nasal catarral, (B) secreção nasal e toxemia e (C) apatia. 
respiração superficial, corrimentos nasais e ocular mucopurulentos e sinais de toxemia ${ }^{42}$ (Figura 2).

Em relação ao exame físico dos bovinos confinados, existe muita resistência por parte dos confinadores para a retirada do animal doente do lote para avaliação das alterações pulmonares por meio da auscultação e percussão pulmonar. Além disso, a identificação do animal doente pela equipe de ronda é muito subjetiva (Figura 3) e pode resultar em diagnósticos errôneos por não identificar e não tratar animais realmente doentes ou por tratar desnecessariamente animais não doentes ${ }^{45}$.

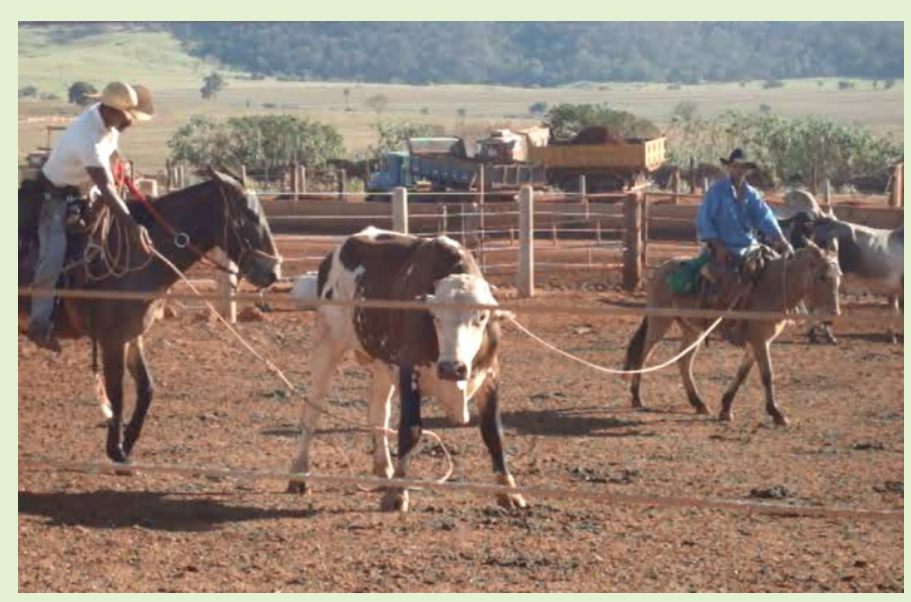

Figura 3. Equipe de ronda sanitária realizando a contenção de animal com sintomatologia de DRB.

\section{DIAGNÓSTICO LABORATORIAL}

A seleção dos testes de diagnóstico baseia-se em vários critérios, incluindo o objetivo do produtor, o histórico, a qualidade da amostra, o laboratório de diagnóstico e o fator econômico ${ }^{46}$.

Para efetuar o diagnóstico, o mais recomendado é selecionar animais na fase aguda da enfermidade e sem antibioticoterapia prévia, haja visto que o tratamento pode reduzir ou anular o crescimento das culturas bacterianas em laboratório ${ }^{46}$. Os agentes etiológicos obtidos por swabs nasais, lavado broncoalveolar ou traqueal e/ou amostras de necropsia podem ser identificados por isolamento viral e bacteriano, reação em cadeia da polimerase (PCR) e imuno-histoquimica ${ }^{47}$. A histopatologia pode auxiliar no diagnóstico com a identificação de lesões características ou sugestivas de alguns agentes e na morfologia de alguns organismos bacterianos ou fúngicos (cocos, bacilos, hifas, etc.), por exemplo.

Embora swabs nasais e nasofaringeos tenham sido usados para isolar BoHV-1 associado à doença respiratória, a identificação de bactérias isoladas como $M$. baemolytica e $M$. bovis são mais difíceis de interpretar, pois esses agentes podem estar presentes como comensais. A técnica de amostragem preferida é lavagem broncoalveolar ${ }^{48}$.

No leucograma, é observado neutrofilia, desvio à esquerda, linfopenia, ou aumento da relação neutrófilos/linfócitos. Esses achados têm sido usados para confirmar inflamação leve a grave em bovinos ${ }^{49}$. Entretanto, em um estudo realizado por Wolfger et al. $^{20}, 52 \%$ das ocorrências naturais de DRB tiveram contagens de leucócitos e neutrófilos maiores em relação aos valores de referência e $20 \%$ tinham contagens de linfócitos acima ou abaixo do intervalo de referência. Considerando a baixa precisão em comparação com sinais clínicos, os autores consideraram de valor limitado a utilização das análises hematológicas para confirmação da DRB em bovinos confinados. Além disso, as proteínas de fase aguda (haptoglobina, amiloide A sérica, fibrinogênio) aumentam em bovinos com inflamação e dano tecidual ${ }^{49}$. Alterações nessas proteínas têm sido associadas à $\mathrm{DRB}$ em estudos de inoculação experimental ${ }^{50,51}$ e de ocorrência natural ${ }^{20,52}$.

O lavado traqueobrônquico e broncoalveolar são técnicas potencialmente úteis para avaliar o estado de saúde do sistema respiratório dos bovinos. As técnicas fornecem acesso ao trato respiratório inferior, permitindo a coleta de amostras que podem auxiliar no diagnóstico do agente causal, na determinação da gravidade da resposta inflamatória, no prognóstico e no tratamento ${ }^{53,54}$. As amostras podem ser avaliadas por meio de técnicas citológicas, que podem indicar pro- 
cesso inflamatório, e análises microbiológicas, como a cultura microbiológica ou a PCR, que permitem o diagnóstico diferencial de doenças virais, bacterianas, parasitárias e fúngicas. A imunocitoquímica para os agentes virais e bacterianos também pode ser realizada em esfregaços diretos para diagnósticos adjuntos rápidos e de baixo custo ${ }^{46}$.

As amostras de lavado broncoalveolar devem ser coletadas, preferencialmente, de animais ainda não tratados, dentro de um a dois dias do início da doença,e mantidas refrigeradas até serem submetidas à cultura bacteriana ou isolamento viral. Atualmente, o isolamento viral é raramente utilizado nos laboratórios de diagnóstico com o advento das técnicas de testes moleculares e imunocitoquímicos para identificação de agentes. $\mathrm{O}$ diagnóstico molecular utilizando a PCR e outras técnicas, proporciona um teste rápido com elevada especificidade e sensibilidade. Porém, os resultados destes testes podem ser alterados por autólise e contaminação bacteriana. Assim, é recomendado que, as amostras para o diagnóstico molecular sejam coletadas o mais rápido possível, livres de contaminação e refrigeradas até o envio ao laboratório ${ }^{46}$.

A citologia por lavado broncoalveolar demonstra ser um indicador sensível da saúde pulmonar e um instrumento potencialmente útil para estudar a DRB. Os macrófagos alveolares constituem aproximadamente $90 \%$ das células presentes no fluido de lavagem e, as demais são representadas por neutrófilos, linfócitos e células epiteliais. Em bezerros com doença respiratória, os desvios à contagem normal de células diferenciais são observados e, normalmente, há diminuição na proporção de macrófagos/neutrófilos, com predominância de neutrófilos ${ }^{55}$.

Fulton et al. ${ }^{56}$ pesquisaram o BCov em bezerros de corte de fonte mista, a partir de um leilão de bovinos, e bezerros de uma só fazenda de origem. O BCov foi isolado em amostras de swab nasal e de lavado broncoalveolar. Esse agente é encontrado nas vias aéreas superiores durante infecções ativas, seu isolamento nas amostras derivadas de pulmão sugere que o $\mathrm{BCov}$ desempenha papel importante nas lesões pulmonares, como pneumonias. $\mathrm{O}$ estudo confirmou que, os bezerros provenientes de fonte mista provavelmente têm infecção ativa pelo BCov no momento da chegada ao confinamento e são considerados uma fonte de contaminação para os demais animais.

Bezerros submetidos ao transporte rodoviário, por um período de quatro horas, foram avaliados por amostras de sangue e de lavado broncoalveolar. Uma elevação acentuada da concentração de cortisol no plasma foi observada após o transporte, sugerindo que esse evento levou os animais a condições estressantes. A quantidade de células fagocitárias no fluido do lavado broncoalveolar, composta principalmente por macrófagos alveolares, diminuiu significativamente após o transporte. Houve também aumento da população de linfócitos $\mathrm{T}$, concluindo-se que, o transporte rodoviário mesmo de curta duração, altera células pulmonares e sua função, o que pode contribuir com distúrbios respiratórios nos bovinos ${ }^{57}$.

\section{DIAGNÓSTICO ULTRASSONOGRÁFICO}

A ultrassonografia torácica (UST) pode oferecer alternativas para identificar lesões pulmonares, pois diferencia as impedâncias dos tecidos e assim produz uma imagem distinta entre o parênquima saudável e as alterações morfológicas do parênquima pulmonar superficial e na pleura, melhorando o diagnóstico e prognóstico da doença ${ }^{58-60}$.

A UST é uma ferramenta de apoio diagnóstico não invasiva, considerada como método sensível para a identificação de lesões pulmonares em diferentes estágios de comprometimento, presumindo o prognóstico do impacto da DRB sobre o desempenho dos animais ${ }^{30,61,62}$. O uso prático da UST foi testado em um estudo que avaliou a concordância entre examinadores ao definirem a presença de consolidação pulmonar e 
demonstrou ser um parâmetro confiável de diagnóstico, mesmo se o operador não tiver experiência no uso de ultrassonografia médica ${ }^{63}$.

As principais alterações identificadas à ultrassonografia são as efusões pleurais, irregularidade pleural, presença de abscessos, consolidação pulmonar, pneumotórax e lesões na parede torácica ${ }^{64}$. A ultrassonografia também pode ser utilizada para orientar a punção do tecido pulmonar e do líquido pleural, para realização de análise citológica e guiar a biópsia percutânea do parênquima pulmonar, para diagnóstico histopatológico ${ }^{65,66}$.

Para a realização do exame ultrassonográfico é necessária a adequada contenção física dos bovinos. Em bovinos de corte, é recomendada a contenção em bretes com abertura lateral direita, ao contrário do que se observa para bovinos de leite, cujo temperamento mais dócil permite que o exame seja feito fora de uma estrutura de contenção ${ }^{59}$. Fatores como o estresse do manejo, tamanho dos animais, espessura da parede torácica, aliados aos riscos de acidentes e barreiras da própria estrutura usada na contenção dos animais limitam o acesso às estruturas pulmonares, exigindo que a avaliação seja rápida e pontual, levando à escolha de uma área específica do tórax ${ }^{67,68}$.

Preferencialmente, é indicado que o exame seja realizado pelo acesso direito, pois há menor influência do rúmen. Além disso, a apresentação das lesões pulmonares foi semelhante entre o lado direito e esquerdo do tórax em bovinos de corte ${ }^{69}$. Timsit et al. ${ }^{30}$ estudaram apenas o lado direito do tórax em 30\% de bovinos confinados e obtiveram resultados semelhantes na avaliação dos impactos negativos na saúde e desempenho dos animais. No entanto, os autores apontam a avaliação de apenas um dos lados como limitante, pois o estudo pode não ter detectado lesões em todos os animais. Portanto, é possível que a avaliação somente de um dos lados subestime o número exato de animais acometidos no rebanho, embora ajude na estimativa da situação do rebanho ${ }^{30,61,68}$.
No preparo para o exame ultrassonográfico de animais que apresentam maior quantidade de pêlos, como os de raças taurinas, é indicada a tricotomia da área de avaliação com tosador elétrico ${ }^{60,70,71}$. Em animais com pelos curtos e macios, é recomendada a utilização apenas de álcool etílico 70 INPM sobre a área para reduzir a presença de sujidades, gordura e o $\operatorname{ar}^{61,66,72}$. Em ambos os casos, é imprescindível a aplicação de gel condutor entre o transdutor e a pele $\mathrm{e}^{61,67}$.

O acesso para visualização das estruturas torácicas ocorre por meio dos espaços intercostais (EIC), com o posicionamento do transdutor em sentido longitudinal, paralelo ao arco costal. Diferentes técnicas de UST foram relatadas como a avaliação do $3^{\circ}, 5^{\circ}$ e $7^{\circ}$ EIC no hemitórax direito ${ }^{67}$, avaliação bilateral do $11^{\circ}$ ao $3^{\circ} \mathrm{EIC}^{59}$ ou o exame da parte cranial direita do pulmão em bezerros ${ }^{62}$. No entanto, para bezerros recém desmamados, a varredura bilateral do hemitórax mostrou-se mais eficaz para estimar a área total acometi$\mathrm{da}^{64}$.

A varredura dos EICs é recomendada em sentido caudocranial e dorsoventral, para ampla descrição das lesões e estimativa da área total comprometida ${ }^{59}$. A visão intercostal do pulmão e pleura pode ser ampliada quando o transdutor é inclinado em sentido cranial ou caudal permitindo a varredura em leque ao longo do $\mathrm{EIC}^{60,73}$.

$\mathrm{Na}$ avaliação torácica são usados transdutores lineares, convexos e setoriais. As frequências dos transdutores podem variar entre 3,5 e 13,0 MHz. É importante considerar que os fatores que levam à escolha da frequência são o tamanho do animal, a espessura da parede torácica e consequente profundidade do pulmão ${ }^{61,64,67,74}$. A utilização do transdutor linear transretal tem sido descrita devido ao formato proporcionar melhor manuseio, principalmente nos $4^{\circ}, 5^{\circ}$ e $6^{\circ} \mathrm{EICs}$, sobrepostos pelo membro torácico ${ }^{60}$. No entanto, de acordo com Ollivett e Buczinski ${ }^{72}$ e Timsit et al. ${ }^{30}$, mesmo com esse modelo de transdutor, os $3^{\circ}, 2^{\circ}$ e $1^{\circ}$ EICs são de difícil acesso em animais adultos. Consi- 

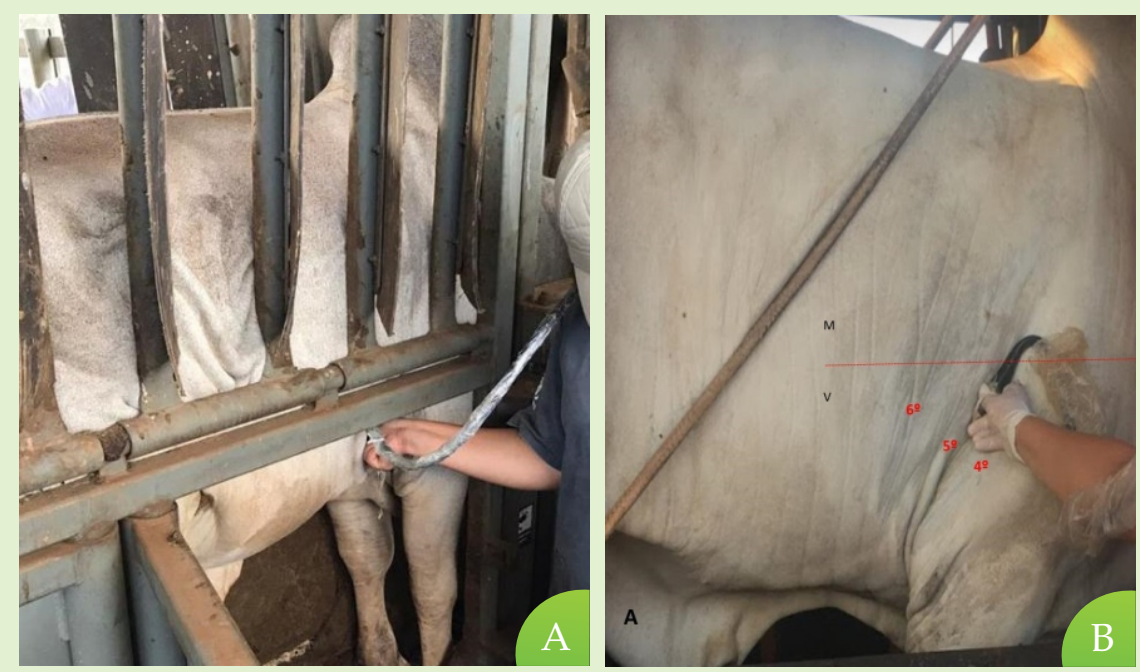

Figura 4. Bovino da raça Nelore contido em brete com cordas adicionais para realização de UST com transdutor linear transretal no intervalo de frequência de 5,0 a 7,0 MHz. (A) Demarcação da área de avaliação (linha vermelha tracejada) em altura média $(\mathrm{M})$ e ventral (V) e dos EICs $6^{\circ}, 5^{\circ}$ e $4^{\circ}$. Posição do transdutor e do examinador para execução do exame e (B) brete com abertura lateral direita do tronco.

derando as condições expostas e a forma de contenção dos bovinos de corte ao realizar exames ultrassonográficos, contatou-se que o emprego do transdutor linear transretal foi o mais adequado, pois permitiu alcançar os espaços intercostais craniais (Figura 4).

No Quadro 1 estão dispostas de forma resumida algumas informações relevantes para a execução do exame ultrassonográfico do tórax de bovinos de diferentes categorias.

$\mathrm{Na}$ análise das imagens obtidas durante o exame ultrassonográfico, a diferença entre as impedâncias acústicas de tecidos moles e alvéolos cheios de ar impede a reconstrução de uma imagem real do pulmão e isso gera vários artefatos, extremamente úteis para a

Quadro 1- Resumo de informações obtidas em diferentes estudos sobre a execução do exame ultrassonográfico em bovinos.

\begin{tabular}{|c|c|c|c|c|c|c|}
\hline Autores & Transdutor & $\begin{array}{l}\text { Frequência } \\
(\mathrm{MHz})\end{array}$ & Animais & $\mathrm{EICS}$ & Lado do tórax & Tricotomia \\
\hline Rabeling et al. ${ }^{75}$ & Setorial & 7,5 & $\begin{array}{l}\text { Bezerros Holstein - } \\
\text { Friesian ( } 5 \text { meses) }\end{array}$ & 3 ao 12 은 & $\mathrm{NI}$ & $\mathrm{NI}$ \\
\hline Babkine e Blond 59 & $\begin{array}{l}\text { Linear ou } \\
\text { setorial }\end{array}$ & 3,5 a 7,5 & BG & 5 음 aо 12 & $A L$ & Sim \\
\hline Abutarbush et al. ${ }^{67}$ & Setorial & 3,5 & $\mathrm{BCRC}$ & $3 ㅇ, 5$ e $7 ㅇ$ & $\mathrm{AL}$ & Sim \\
\hline Rademacher et al. 69 & $\begin{array}{l}\text { Linear } \\
\text { transretal }\end{array}$ & 5 a 8 & BCRC & 4 으 aо $10^{\circ}$ & $\mathrm{AL}$ & Não \\
\hline Buckzinski et al. 64 & $\begin{array}{l}\text { Linear } \\
\text { transretal }\end{array}$ & 6,5 & BCRC & $\mathrm{NI}$ & $\mathrm{NI}$ & $\mathrm{NI}$ \\
\hline Timsit et al. ${ }^{30}$ & Linear & 6,5 & BCRC & 45 e 60 & $\begin{array}{c}30 \% \text { do ado direito e } \\
70 \% \mathrm{AL}\end{array}$ & Não \\
\hline Braun et al. 60 & $\begin{array}{l}\text { Linear, } \\
\text { convexo, } \\
\text { setorial e } \\
\text { transretal }\end{array}$ & $3,5-13$ & $B G$ & 3으 ao 11 응 & $\mathrm{AL}$ & Sim \\
\hline
\end{tabular}

Legenda: $\mathrm{EICs}=$ Espaços intercostais, $\mathrm{BCRC}=$ Bezerros de corte recém confinados, $\mathrm{BG}=$ Bezerros em geral, $\mathrm{AL}=\mathrm{Ambos}$ os lados e $\mathrm{NI}=\mathrm{Não}$ informado. 
interpretação de alterações torácicas. Uma forma de auxiliar na interpretação das imagens é a confecção de vídeos curtos durante a execução do exame, como recomendado por Timsit et al. ${ }^{30}$, permitindo a reavaliação das alterações posteriormente, especialmente para a verificação de movimentação pleural.

As pleuras parietal e visceral hiperecoicas, apresentam-se na UST justapostas e com movimento deslizante em conjunto com a respiração. Além disso, as pleuras apresentam-se com formato linear e limites regulares. Contudo, em lesões envolvendo-as podem apresentar-se irregulares, espessadas e/ou fragmentadas em casos de efusões pleurais, irregularidade pleural, aderências e pneumotórax ${ }^{58,60,76}$. A observação do deslizamento das pleuras pode auxiliar em qual porção o processo patológico está presente, pois a pleura visceral se movimenta de acordo com a respiração, enquanto a parietal permanece fixa. No entanto, se as duas pleuras não se movimentam é indicativo de aderência pleural, que pode ser localizada ou difusa ${ }^{59,77}$.

Outra alteração possível de ser detectada é o distanciamento das pleuras causado pela presença de líquido (Figura 5). A característica anecoica na ultrassonografia pode indicar transudado de baixa celulari- dade e baixo conteúdo protéico (incluindo fibrinoso), como ocorre na congestão passiva, ou característica mais densa e ecoica, no caso de exsudatos, devido a presença de células, podendo apresentar filamentos de fibrina em casos de pleurites ${ }^{60}$. Nesses casos, a ultrassonografia pulmonar ainda pode auxiliar na identificação do local para drenagem, nos processos de toracocente$\mathrm{se}^{73,78}$

O diagnóstico dos distúrbios que levam ao acúmulo de líquido entre as pleuras é visualmente fácil de ser concluído, diferentemente dos casos de pneumotórax. Nessa condição, o ar se interpõe entre a parede torácica e o pulmão, visto como descontinuidade da pleura e interferência das reverberações produzidas por esse ar. Sendo que, os artefatos referentes ao pulmão acompanham o movimento da expansão torácica e em contrapartida, os artefatos gerados pelo ar entre as pleuras permanecem e sobrepõe o campo pulmonar na expiração ${ }^{59,79}$.

No pulmão saudável, sob a pleura são visualizadas linhas horizontais distribuídas uniformemente, denominadas linhas $\mathrm{A}$, que são resultantes de um efeito de reverberação das ondas ${ }^{66}$. Ao se estabelecer um processo inflamatório que cursa com o comprometimento
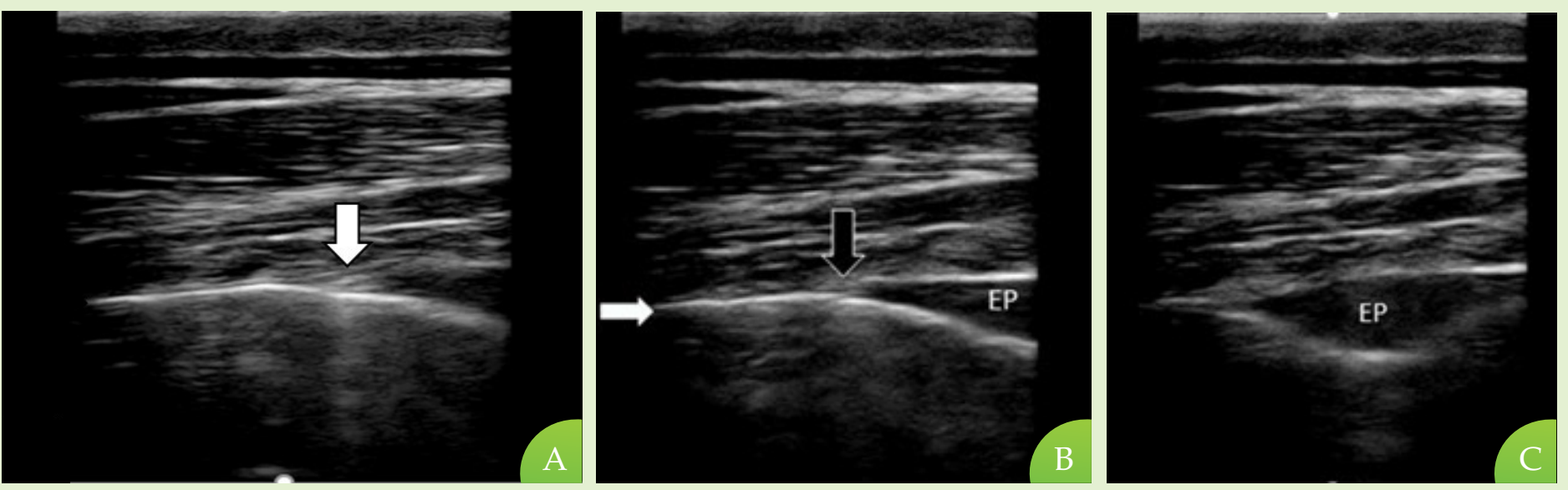

Figura 5. Ultrassonografia do pulmão de um bovino Nelore aos vinte dias de confinamento. Imagens obtidas na porção ventral do $5^{\circ} \mathrm{EIC}$ direito em avaliação sequencial de acompanhamento dos diferentes momentos da respiração. Em A, B e C notar pleuras justapostas, retilíneas e hiperecoicas, apontadas pela seta branca e ponto de distanciamento das pleuras marcado pela seta preta, com surgimento de imagem anecoica indicativa da presença de líquido interpleural (EP). Transdutor linear transretal em $5,0 \mathrm{MHz}$ e profundidade de $10 \mathrm{~cm}$. 
do interstício, como na broncopneumonia, a região abrangida pode apresentar ventilação preservada não sendo possível visualizar alteração do parênquima. Nesse caso, há visualização das linhas B, ou "cauda de cometa", que são expressões de descontinuidades resultantes da constante oposição entre o ar alveolar e os fluidos no interstício. As "caudas de cometa" ou linhas $\mathrm{B}$, geralmente começam da pleura em forma de um feixe estreito vertical de linhas hiperecogênicas muito próximas, que se movimentam em sincronia com o movimento respiratório, por isso são melhor identificadas no momento do exame, ou em vídeos que permitam a avaliação dos movimentos respiratórios ${ }^{80}$.

Na medida que há progressão no comprometimento alveolar, há perda desses artefatos formados pela presença de ar, pois há preenchimento dos alvéolos, formando uma imagem de um tecido hipoecoico, homogêneo ou heterogêneo, com evidente diferenciação das estruturas, denominadas por consolidações. Essas lesões correspondem a alvéolos que são preenchidos com líquido, material celular ou lobos pulmonares ateletásicos ${ }^{59,64}$.

A consolidação pulmonar é um dos achados mais comuns de UST associado ao prognóstico desfavorável $^{59,63,69}$. Em geral, as consolidações podem ser mensuradas quanto a profundidade e extensão, sendo que lesões com profundidade maior que $5 \mathrm{~cm}$ e área superior a $8 \mathrm{~cm}^{2}$ estão relacionadas à recidivas e prognósticos desfavoráveis, que podem influenciar significativamente no ganho de peso ou até levar os animais à morte ${ }^{30,69}$. No entanto, estudos que identificaram alterações mais discretas, como artefatos de "cauda de cometa" e pontos de efusão pleural, não demonstraram até então relação entre esses achados e a queda no ganho de peso diário ou recidivas de broncopneumoni$\mathrm{as}^{30,69}$.

Diante das informações disponíveis na literatura, se espera um cenário favorável para o uso da UST no diagnóstico de lesões pulmonares. Ainda não é possível distinguir lesões ativas da infecção pulmonar de lesões residuais, ou sequelas de doenças anteriores, portanto, as informações obtidas a partir da avaliação de UST são usadas para quantificar lesões, estimar a área de comprometimento e associar aos impactos na produção.

\section{DIAGNÓSTICO POST MORTEM}

Mais investigações sobre o impacto da DRB em confinamentos de diversas regiões do Brasil são necessárias para se ter uma visão geral dos efeitos nacionais dessa doença nos rebanhos de bovinos de corte. Acompanhar o abate dos animais e realizar inspeções dos pulmões é uma ferramenta de triagem importante como método de diagnóstico e suporte dos rebanhos, haja vista poder auxiliar nas medidas de controle e prevenção das doenças e evitar grandes prejuízos econômicos ${ }^{11}$. Lesões pulmonares foram confirmadas em 8,3\% de 1.617 animais abatidos em um matadouro comercial em São Paulo ${ }^{11}$ e em 12,78\% de 2.129 bovinos inspecionados em frigoríficos no estado de Goiás ${ }^{15}$.

Em um estudo com 469 bovinos, investigouse a incidência de lesões nos pulmões e descobriram que dos bovinos tratados para DRB (35\%), 72\% tinham lesões pulmonares no momento do abate, e que $68 \%$ dos bovinos não selecionados para tratamento apresentaram lesões nesse órgão. A avaliação de desempenho alimentar indicou também que, os bovinos com lesões pulmonares tiveram ganho de peso médio diário reduzido. Esse achado confirmou que a detecção visual de DRB é imprecisa e que o desempenho, assim como perdas monetárias causadas pela doença, são significativos ${ }^{81}$.

Em uma pesquisa que associou lesões pulmonares em novilhos com sinais clínicos e tratamento para DRB, comparando-os com um grupo de novilhos sem sinais e não tratados, concluiu-se que os animais tratados e recuperados não compensaram o desempenho perdido no lote. Além disso, a incidência de lesão pulmonar alta (37\%) nos novilhos com DRB subclíni- 
ca indicou diagnósticos clínicos imprecisos para seleção e tratamento dos bovinos. Essa imprecisão do diagnóstico clínico da DRB pode justificar o uso de medicação em massa, particularmente quando há previsão de morbidade significativa em um grupo ${ }^{82}$.

A avaliação de lesões à necropsia é outro método comprovado para determinar a precisão do diagnóstico e a resposta terapêutica ${ }^{13}$. A necropsia deve ser realizada em animais doentes e não tratados, submetidos à eutanásia ou em bovinos encontrados mortos dentro de poucas horas. Além disso, a realização de histopatologia, PCR, sorologia e cultura bacteriana podem ser capazes de caracterizar as lesões da doença e os possíveis agentes causais responsáveis ${ }^{46}$.

A avaliação macroscópica do pulmão deve ser cuidadosa e acompanhada da descrição detalhada dos achados quanto a localização, distribuição e extensão da lesão nos diferentes lobos pulmonares. Além disso, as lesões macroscópicas do trato respiratório causadas pela DRB podem ser observadas por alteração da coloração, textura e distribuição das lesões. Os principais achados incluem diferentes tonalidades de vermelho que podem indicar hiperemia, hemorragia ou ambas; coloração vermelho escuro com áreas consolidadas características de atelectasia; áreas róseo-claras ou esbranquiçadas associadas à anemia, enfisema ou fibrose; deposição de material amarelado na superfície pleural indicativa de exsudação fibrinosa, purulenta ou ambas e textura firme em áreas de consolidação, fibrose ou formação de nódulos ${ }^{83,84}$.

$\mathrm{Na}$ presença de alteração macroscópica pulmonar, o tecido alterado deve ser coletado numa área adjacente a uma região sem alteração, para identificação da lesão no exame histopatológico. Para essa análise, o material obtido deverá ser acondicionado em solução fixadora, como formalina tamponada a 10\%, em proporção de dez a vinte vezes o volume do fixador para um do tecido. Os fragmentos pulmonares coletados rotineiramente são processados e corados por hematoxilina e eosina (HE). Vale ressaltar que o histo- patológico é importante para confirmar as suspeitas da avaliação macroscópica. Nesse exame é possível visualizar lesões específicas como atelectasia, enfisema, edema, hemorragia, necrose, inflamação, bronquite e pleurite, e também pode diagnosticar tipos específicos de pneumonias, que são caracterizadas por um conjunto de lesões microscópicas ${ }^{83,84}$.

A broncopneumonia pode ser classificada, de acordo com o exsudato, em supurativa ou fibrinosa. Macroscopicamente, essa lesão é caracterizada por consolidação irregular na região crânio-ventral dos lobos craniais, de coloração vermelho escuro a acinzentado (Figura 6A). Microscopicamente, verifica-se infiltrado predominante de neutrófilos, mas também de linfócitos, plasmócitos e macrófagos na luz de brônquios e bronquíolos, bem como na junção destes com os alvéolos, a qual é causada por infecções bacterianas, que chegam ao pulmão usualmente por via aerógena. Essa exsudação inflamatória pode vir acrescida de deposição de fibrina no interior dos alvéolos e bronquíolos ${ }^{83,85}$. A broncopneumonia supurativa, quando aguda possui exsudato no interior dos brônquios de purulento a mucopurulento ${ }^{86} \mathrm{e}$ os estágios iniciais mostram edema e deposição de fibrina com congestão ou hemorragia nos alvéolos, juntamente com neutrófilos e macrófagos (Figura 6B). Em estágios mais avançados, os alvéolos contêm neutrófilos degenerados com núcleos hipercromáticos, indicando toxicidade celular e morte celular. Agregados bacterianos podem ser observadas junto aos focos de necrose circundadas por tecido fibroso ${ }^{87}$. $\mathrm{Na}$ presença de lesão crônica, macroscopicamente, a consolidação se torna mais irregular, podendo ocorrer bronquiectasia, formação de abcessos e fibrose lobu$\operatorname{lar}^{85}$.

$\mathrm{Na}$ pneumonia intersticial observam-se, na macroscopia, áreas difusas e não colapsadas de consolidação, principalmente, na região dorso-caudal dos pulmões (Figura 7A). Na microscopia, é possível visualizar espessamento e infiltrado inflamatório de septos alveolares ou interlobulares (interstício), e sua principal 

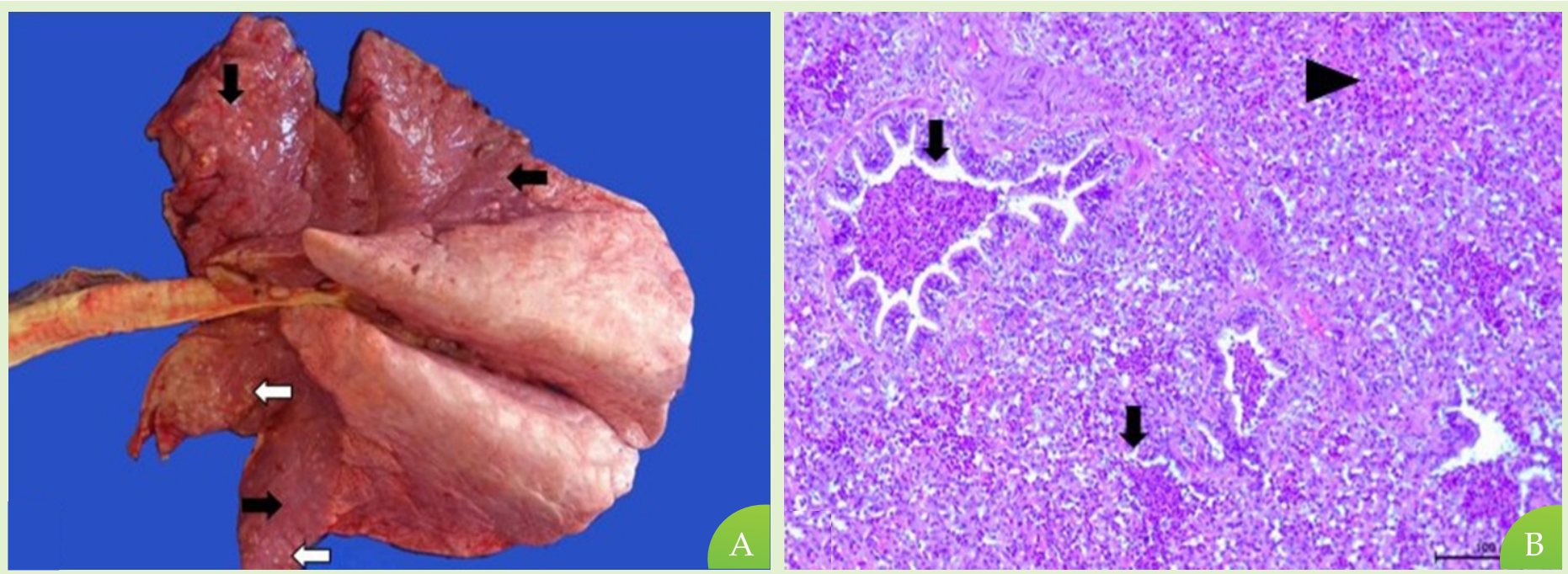

Figura 6. Pulmão bovino com quadro de broncopneumonia supurativa. (A) Comprometimento das regiões ântero-ventrais dos lobos craniais, que se encontram aumentadas, firmes e escuras (setas pretas). Nessa área, notam-se numerosos nódulos milimétricos e brancos consistentes com exsudato purulento (setas brancas). (B) Fotomicrografia: infiltrado inflamatório neutrofílico em espaço alveolar e bronquíolo acentuado e difuso (seta), hemorragia e necrose focal discreta (cabeça de seta), HE, 20X.

via de infecção é a hematógena. Essa pneumonia geralmente possui caráter crônico e caracteriza-se por resposta proliferativa e fibrótica e pode ser causada por vários agentes infecciosos (Figuras 7B e C), especialmente vírus ${ }^{83,85}$.
A pneumonia granulomatosa é um processo crônico que se caracteriza, macroscopicamente, pela presença de nódulos focais ou multifocais a coalescentes (granulomas) no parênquima pulmonar. Essa lesão é especialmente causada por bactérias álcool ácido
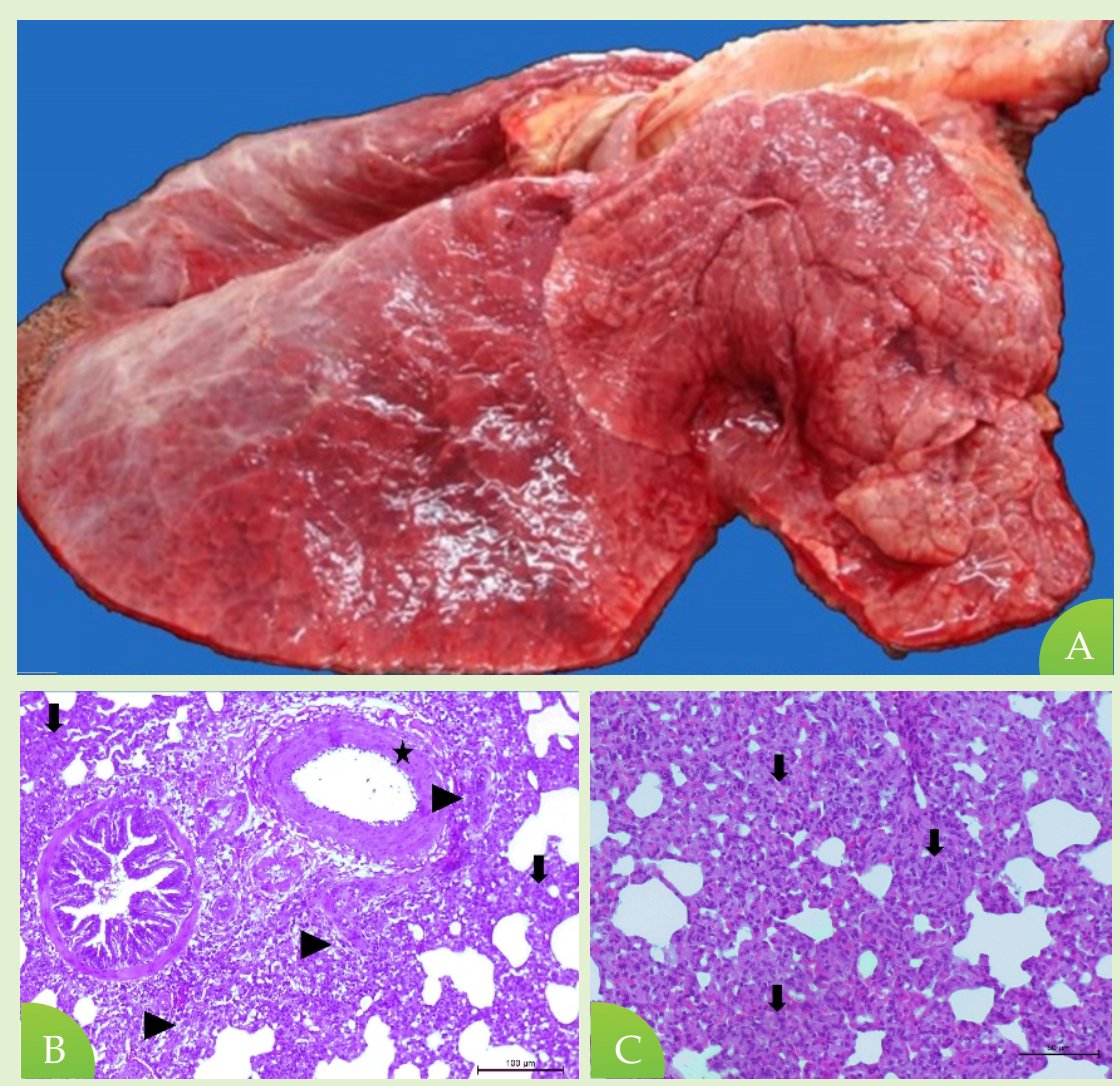

Figura 7. Pulmão de bovino jovem apresentando pneumonia intersticial. (A) Pulmão onde os lobos não colapsaram após abertura da cavidade torácica e estão difusamente vermelho escuro. (B e C) Fotomicrografia: (B) Espessamento septal, infiltrado inflamatório linfocitário e mononuclear em septos alveolares acentuado e difuso (seta), proliferação fibroblástica discreta focal (cabeça de seta) e (C) espessamento septal, infiltrado inflamatório linfocitário e mononuclear em septos alveolares acentuado e difuso (seta), HE, 40X. 

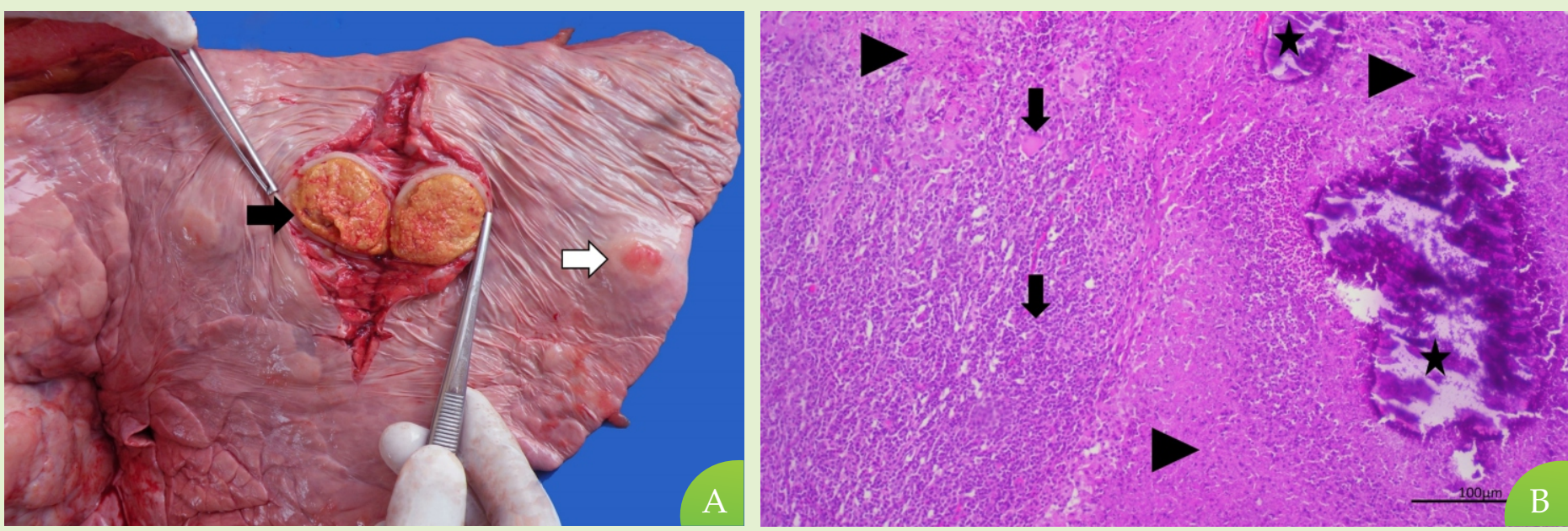

Figura 8. Pneumonia granulomatosa em bovino. (A) Pulmão apresenta dois granulomas: um cortado (seta preta) e outro íntegro (seta branca). As lesões são caracterizadas por área focal e bem delimitada de necrose de caseificação envolta por cápsula fibrosa. Essa área rangia ao corte da faca, devido à deposição de minerais (mineralização distrófica) (Crédito: Prof. Claudio Severo Lombardo de Barros). (B) Fotomicrografia, pulmão, bovino, pneumonia granulomatosa: infiltrado inflamatório granulomatoso (seta) circundado por infiltrado linfocitário, calcificação discreta multifocal (estrela), necrose caseosa multifocal (cabeça de seta),HE,20X.

resistentes e por fungos, que alcançam o pulmão usualmente por via aerógena. A tuberculose é um bom exemplo de enfermidade que cursa com esse tipo de pneumonia em bovinos. As lesões granulomatosas são caracterizadas por área central e extensa de necrose caseosa (Figuras 8A e B), muitas vezes com mineralização distrófica, envolvidas por halo de inflamação rico em macrófagos epitelióides, linfócitos, plasmócitos e células gigantes multinucleadas (principalmente do tipo Langerhans) e, externamente, por cápsula fibrosa conjuntiva $^{85}$.É comum a evidenciação de lesões granulomatosas adicionais de aspecto muito similar nos linfonodos (especialmente os mediastínicos e traqueobrônquicos) de bovinos com tuberculose.

\section{TRATAMENTO}

As ações terapêuticas contra as doenças respiratórias em bovinos não são direcionadas para a infecção viral, mas sim para as infecções bacterianas secundárias. $\mathrm{O}$ tratamento dos bovinos com $\mathrm{DRB}$ inicia-se com a retirada do animal doente do curral para evitar a disseminação do agente. $\mathrm{O}$ isolamento proporcionará a redução do estresse no animal afetado, permitirá o acompanhamento da evolução clínica e aumentará o acesso à água e alimentos. Informações referentes à identificação do animal, data de chegada, peso, dias de tratamento e protocolo de tratamento (dosagem, carência, via de administração, etc) devem obrigatoriamente serem registradas ${ }^{46}$.

A seleção do antimicrobiano depende de vários fatores que podem incluir: afinidade pulmonar, via de administração, sensibilidade do patógeno e a carência do produto ${ }^{8}$, além de custo, número de doses e possibilidade de ocasionar reações adversas. Antiinflamatórios não esteroidais (AINEs) têm sido utilizados com objetivo de reduzir a pirexia e diminuir a gravidade dos sinais clínicos e lesões pulmonares ${ }^{48}$.

Nas últimas décadas vários agentes antimicrobianos foram aprovados nos EUA para o tratamento de DRB, dentre eles: ampicilina, ceftiofur, danofloxacina, enrofloxacina, florfenicol, gamitromicina, oxitetraciclina, penicilina, tilmicosina, tilosina, tildipirosina e tulatromicina ${ }^{88}$. No entanto, já existem genes de resistência descritos para alguns agentes da DRB para a maioria dessas bases antimicrobianas ${ }^{88}$, o que 
leva a grandes prejuízos à indústria da carne ${ }^{89}$.

No Brasil, os antimicrobianos mais utilizados para tratamento de DRB nos confinamentos são benzilpenicilina benzatina, florfenicol, enrofloxacina, tilmicosina, tulatromicina, marbofloxacina, gamitromicina e a tildipirosina. Embora, a maioria dos animais tratados para DRB responda diretamente, após o tratamento inicial ou tratamentos adicionais, alguns animais desenvolvem forma crônica, que é considerada não responsiva à terapia antimicrobiana ${ }^{90,91}$.

A avaliação da resposta terapêutica é fundamental para determinar se os protocolos de tratamento são eficazes. Essa avaliação pode ser realizada por meio de avaliação semanal ou mensal dos registros de morbidade e mortalidade. A taxa de letalidade (TL) é um bom meio de verificar a capacidade do funcionário na identificação dos animais doentes de forma eficaz, tratar e verificar a resposta ao tratamento. A TL pode ser obtida pela divisão do número de mortes por DRB pelo número de bovinos tratados inicialmente para a doença e multiplicada por 100. Uma TL aceitável é entre $6 \%$ e $10 \%$ e pode variar com base na raça e no risco ao qual o rebanho é submetido. Bezerros de alto risco podem atingir uma TL superior a $15 \%{ }^{13}$.

Quando o indicador de letalidade está alto, o problema pode não ser o medicamento em si, mas a sua aplicação. Diante da ineficácia do tratamento, o usual nos confinamentos é trocar o princípio ativo. Entretanto, atenção a ocorrência de subdosagem deve ser monitorada por meio de indicador denominado "desvio de dose", que mede a diferença entre as doses aplicadas (registradas na planilha da fazenda) e as recomendadas para cada produto, conforme o peso do animal. Manejo inadequado para realizar a medicação favorece desperdício de medicamento, principalmente quando a contenção do animal doente é feita nos currais ("no laço"), gerando erros na dose. O ideal é imobilizar o animal em um tronco de contenção para realizar a medicação com objetivo de pesá-lo (balança ou fita torácica para estimar o peso vivo do animal), proporcionando inclu- sive maior segurança para o animal (fraturas) e/ou funcionário (traumatismos) ${ }^{5}$.

\section{PREVENÇÃO E CONTROLE}

A alta frequência de DRB nos confinamentos associada ao elevado preço do boi magro tem estimulado o confinador a atentar-se para estabelecimento de medidas de controle e profilaxia. Os mais utilizados estão relacionados à metafilaxia (uso de antimicrobianos no lote) ou a profilaxia (vacina) ${ }^{92}$.

A metafilaxia é uma estratégia baseada no conceito de tratamento em massa de bovinos identificados com alto risco de desenvolverem $\mathrm{DRB}$, que inclui o uso de antimicrobiano injetável, de amplo espectro, ação prolongada, que permite dose única como parte do protocolo e tem o objetivo de diminuir a carga do patógeno em casos clínicos e subclínicos ${ }^{41,92,93}$. Os resultados do uso da metafilaxia indicam melhor desempenho produtivo e redução da taxa da doença de $20 \%$ a $44 \%$ e de zero a $24 \%$ nas perdas por mortes de animais confinados ${ }^{41,92,94}$.

No Brasil, os protocolos metafiláticos com oxitetraciclina e tildipirosina foram eficientes em relação à morbidade e lesões pulmonares em bovinos confinados ${ }^{95}$. Barbosa et al. ${ }^{96}$ concluíram que, o enrofloxacino pode ser usado com sucesso como metafilático em animais confinados, proporcionando a redução de doenças respiratórias e aumentando o ganho de peso dos animais.

O momento mais comum para se administrar a metafilaxia é durante os procedimentos iniciais do confinamento, que é quando o estresse e a exposição aos patógenos em bezerros de alto risco são elevados ${ }^{13}$. As diretrizes gerais que têm impacto na decisão de administrar o tratamento metafilático para DRB inclui animais com baixo escore corporal (peso leve), bovinos de múltiplas origens, longas viagens $(>500 \mathrm{~km}$ e/ou oito horas de viagem), índices atuais (e esperados) de morbidade e mortalidade e temperatura corporal ele- 
$\operatorname{vada}^{41}$.

Uma meta-análise foi realizada para determinar a eficácia comparativa de antimicrobianos injetáveis, de forma metafilática, utilizados em bovinos de corte para o controle da DRB nos primeiros 45 dias de confinamento. Os macrolídeos foram considerados o grupo de antimicrobianos mais eficaz para a redução da incidência da DRB, sendo os tratamentos com tulatromicina, gamitromicina, tildipirosina e tilmicosina os mais bem classificados. O ceftiofur e a oxitetraciclina obtiveram os próximos "rankings" mais altos, respectivamente, depois dos macrolídeos ${ }^{97}$.

O uso da metafilaxia é polêmico, pois consumidores e autoridades de saúde estão cada vez mais exigindo limites ao uso de antimicrobianos nos animais de produção. A diminuição do uso de terapia antimicrobiana pode ajudar a reduzir a resistência aos antimicrobianos $^{91,98-100}$. Existem estudos epidemiológicos em andamento para avaliar a resistência a antimicrobianos entre patógenos bacterianos humanos e a relação com o uso de antimicrobianos nos animais de produção. É muito possível que, muitos dos antimicrobianos que os confinadores usam hoje percam eficácia no futuro. Por essa razão, torna-se muito importante que, os confinadores sejam orientados ao uso correto dos antimicrobianos, não somente como metafilaxia, mas também como terapêutica de forma criteriosa.

Em grandes confinamentos, a associação da vacinação e práticas de manejo profiláticos da mortalidade e da morbidade por DRB auxilia na redução dos desafios sanitários ${ }^{41}$. A vacinação não é um método que assegura a ausência da doença, mas é uma ferramenta que pode reduzir o número de ocorrências em uma população, principalmente quando identificados os grupos com maior risco para uma doença ${ }^{101}$. Além disso, existem muitos fatores que devem ser considerados ao tomar decisões sobre as estratégias de imunização, dentre os quais: a natureza e disseminação do agente, a probabilidade de exposição à doença, os riscos econômicos, a eficácia, segurança e disponibilidade de vaci- nas aprovadas, os custos totais e a viabilidade da imunização $^{13}$.

Inúmeros tipos de vacinas (vivas modificadas e vacinas inativadas) estão disponíveis no mercado nacional com antígenos virais como BoHV-1, BVDV, BPI$3 \mathrm{~V}$ e VSRB, associados ou não a antígenos bacterianos como $M$. haemolytica, P. multocida e H. somni. A via de administração subcutânea ou intramuscular são as mais utilizadas, embora exista no mercado vacina com aplicação por via intranasal $1^{102,103}$.

Cada confinamento apresenta uma realidade sanitária e nutricional diferente, seja por conta da densidade dos lotes, desafios climáticos e índices de morbidade e mortalidade. Não existe um programa sanitário suficiente para garantir 100\% de eficiência. Além disso, o calendário sanitário precisa de personalização própria em cada propriedade para que se obtenha máximo de resultado. $O$ protocolo de vacinação vai depender se o confinamento utiliza animais recriados na própria fazenda ou se a aquisição ocorre em leilões/parceiros.

Os confinamentos que recebem bovinos recriados na própria fazenda podem realizar o protocolo sanitário em duas etapas: trinta dias antes da entrada no confinamento e no dia do processamento para distribuição dos bovinos nos currais. Esse tipo de manejo permite que animais não vacinados (primovacinação) recebam duas doses (doença respiratória) com intervalo de 21 a 30 dias. Outra vantagem dessa estratégia é a possibilidade de realizar pré-confinamento trinta dias antes da entrada dos animais. Essa ação proporciona benefício direto sobre a manutenção do crescimento animal, que durante o período de engorda estarão acostumados com maiores quantidades de concentrado, facilitando a adaptação a novas dietas. Adicionalmente, o adiantamento no momento da vacinação contra patógenos de $\mathrm{DRB}$, ou seja, o fornecimento da vacina antes de se entrar no confinamento, pode mitigar a incidência de DRB e melhorar o desempenho dos bovinos no sistema de confinamento comercial ${ }^{11,103}$.

A maioria dos confinamentos adquirem 
animais em leilões (sem histórico prévio de vacinação) e/ou recebem de parceiros. Os bovinos chegam no confinamento e passam por período de 48 a 72 horas para descanso e reposição hídrica e alimentar para depois receberem protocolo sanitário. Nesse modelo, somente é possível realizar uma dose da vacina respiratória porque os confinadores não retornam com os lotes após 21 a 30 de entrada no confinamento para realizar dose de reforço. Justificam que a movimentação dos animais acarreta estresse e possíveis traumas. É improvável que apenas uma dose vacinal na chegada dos animais seja efetivo no controle das doenças respiratórias nos confinamentos $^{104}$. E segundo Edwards ${ }^{13}$, um programa estratégico iniciando nas unidades de recria assegura- ria a chegada de animais ao confinamento com imunidade suficiente para suportar os desafios.

O uso de vacinas é controverso e gera discussões sobre sua eficácia no confinamento ${ }^{105}$. A imunidade induzida pela vacina pode levar de 14 a 21 dias para se desenvolver ${ }^{13}$ e fatores de risco para morbidade de DRB podem ocorrer antes da chegada do confinamento, incluindo aqueles relacionados a mistura de animais de diferentes fazendas de origem (leilão), transporte e jejum durante o transporte ${ }^{8,13}$. Assim, o controle de DRB pode ser melhor realizado focando nesses fatores de risco ${ }^{97}$.

\section{CONSIDERAÇÕES FINAIS}

Os confinamentos têm lidado com os desafios e consequências das DRB. O conhecimento da tríade epidemiológica (agente, ambiente e hospedeiro), a identificação dos fatores de risco e a realização dos exames ante mortem e post mortem devem fazer parte da estratégia para reduzir os índices de morbidade e mortalidade e os custos da DRB. As informações obtidas a partir dessas avaliações são muito relevantes na tomada de decisões e recomendações futuras. Antimicrobiano e vacinas ainda são utilizadas como os métodos padrão de terapia, controle e prevenção de DRB. Com a profissionalização dos confinamentos brasileiros, a gestão sanitária exigirá maior planejamento com protocolos de diagnóstico, tratamento e prevenção mais eficientes.

\section{REFERÊNCIAS}

1. GestAgro $360^{\circ}$. Resultados de 2020 levam a projeções positivas para 2021,2020.

2. SCOT CONSULTORIA. Benchmarking Confina Brasil.2021.35p.

3. DSM. Censo de Confinamento DSM 2019 registra crescimento do rebanho confinado no Brasil,2021.

4. MARTINS, R.A. Estudo da morbidade e mortalidade em confinamentos de bovinos para terminação e seus impactos econômicos. 2016. 91f. Dissertação (Mestrado em Ciência Animal) - Escola de Veterinária, Universidade Federal de Minas Gerais, Belo Horizonte, Minas Gerais.

5. VILELLA, R. Gestão sanitária à vista do produtor. DBO, ano 39, n.484, p.36-42, 2021.

6. SANDERSON, M.A. et al. Risk factors for initial respiratory disease in United States feedlots based on producer-collected daily morbidity counts. Canadian Veterinary Journal, v.49, n.4,p.373-378,2008. 
7. WILSON, B.K. et al. Evaluation of multiple ancillary therapies used in combination with an antimicrobial in newly received high-risk calves treated for bovine respiratory disease. Journal of Animal Science,v.93, n.7, p.3661-3674,2015.

8. CUSACK, P.M. et al. The medicine and epidemiology of bovine respiratory disease in feedlots. Australian Veterinary Journal,v.81, n.8,p.480-487,2003.

\section{CHURCH, T.L.; RADOSTITS, A.M. A retro-} spective survey of diseases of feedlot cattle in Alberta. Canadian Veterinary Journal,v.22, n.2,p.27-30,1981.

10. MALAFAIA, P. et al. Principais problemas sanitários e seu impacto econômico em bovinos de corte criados em diferentes tipos de confinamento no Brasil. Pesquisa Veterinária Brasileira, v.36, n.9, p.837-843, 2016.

11. BAPTISTA, A.L. et al. Bovine respiratory disease complex associated mortality and morbidity rates in feedlot cattle from southeastern Brazil. Journal of Infection in Developing Countries, v.11, n.10, p.791$799,2017$.

12. CALLAN, R.J.; GARRY, F.B. Biosecurity and bovine respiratory disease. Veterinary Clinics of North America: Food Animal Practice, v.18, n.1, p.57-77,2002.

13. EDWARDS, T.A. Control methods for bovine respiratory disease for feedlot cattle. Veterinary Clinics of North America: Food Animal Practice, v.26, n.2, p.273284,2010 .

14. SINGH, K. et al. Mannheimia haemolytica: bacterial-host interactions in bovine pneumonia. Veterinary Pathology,v.48, n.2,p.338-348,2011.

15. CERQUEIRA, A.B. Doença respiratória em bovi- nos confinados: aspectos patológicos e de desempenho produtivo. 2017.54f. Dissertação (Mestrado em Ciência Animal) - Escola de Veterinária e Zootecnia, Universidade Federal de Goiás, Goiânia, Goiás.

16. ADAMS, E.A.; BUCZINSKI, S. Short communication: ultrasonographic assessment of lung consolidation postweaning and survival to the first lactation in dairy heifers. Journal of Dairy Science, v.99, n.2, p.14651470,2016

17. BLAKEBROUGH-HALL, C. et al. An evaluation of the economic effects of bovine respiratory disease on animal performance, carcass traits, and economic outcomes in feedlot cattle defined using four BRD diagnosis methods. Journal of Animal Science, v.98,n.2,p.1-11,2020.

18. HEADLEY, S.A. et al. Bovine respiratory disease associated with Histophilus somni and bovine respiratory syncytial virus in a beef cattle feedlot from southeastern Brazil. Semina: Ciências Agrarias, v.38, n.1, p.283-294,2017.

19. HEADLEY, S.A. et al. Histophilus somni is a potential threat to beef cattle feedlots in Brazil. Veterinary Record,v.175, n.10,p.249,2014.

20.WOLFGER, B. et al. A systematic review of bovine respiratory disease diagnosis focused on diagnostic confirmation, early detection, and prediction of unfavorable outcomes in feedlot cattle. Veterinary Clinics of North America: Food Animal Practice, v.31, n.3, p.351$365,2015$.

21. VAN VUUREN, M.Parainflueza type 3 infections. In: COETZER, J.A.W.; TUSTIN, R.C. (Ed). Infectious disease of livestock. Oxford: Oxford University Press, 2004.p.673-676. 
22. SNOWDER, G.D. et al. Bovine respiratory disease in feedlot cattle: phenotypic, environmental, and genetic correlations with growth, carcass, and longissimus muscle palatability traits. Journal of Animal Science, v.85, n.8, p.1885-1892,2007.

23. KNOWLES, G.A review of the road transport of cattle. Veterinary Record.,v.144, n.8, p.197-201,1999. 24. SWANSON,J.C.; MORROW-TESCH, J. Cattle transport: historical, research, and future perspective. Journal of Animal Science, v.79, e102-e109,2001.

25. MACVEAN, D.W. et al. Airborne particle concentration and meteorologic conditions associated with pneumonia incidence in feedlot cattle. American Journal of Veterinary Research, v.47, n.12, p.2676-2682, 1986.

26. FULTON, RW. Host response to bovine viral diarrhea virus and interactions with infectious agents in the feedlot and breeding herd. Biologicals, v.41, n.1, p.31-38,2013.

27. HOLMAN, D.B. et al. The nasopharyngeal microbiota of feedlot cattle that develop bovine respiratory disease. Veterinary Microbiology, v.180, n.1-2, p. $90-95,2015$.

28. HALL, J.A. et al. Weaned beef calves fed seleniumbiofortified alfalfa hay have an enriched nasal microbiota compared with healthy controls. PLoS One, v.12,n.6, e0179215, 2017.

29. STROEBEL, C. et al. Effects of transportation to and comingling at an auction market on nasopharyngeal and tracheal bacterial communities of recently weaned beef cattle. Veterinary Microbiology, v.223, p.126-133,2018.

30. TIMSIT, E. et al. Association of lung lesions mea- sured by thoracic ultrasonography at first diagnosis of bronchopneumonia with relapse rate and growth performance in feedlot cattle. Journal of Veterinary Internal Medicine,v.33, n.3,p.1540-1546,2019.

31. AMAT, S. et al. Probiotic bacteria inhibit the bovine respiratory pathogen Mannheimia haemolytica serotype 1 in vitro. Letters in Applied Microbiology, v.64, n.5,p.343-349, 2017.

32. AMAT, S. et al. Development of bacterial therapeutics against the bovine respiratory pathogen Mannheimia haemolytica. Applied and Environmental Microbiology, v.85, n.21,p.1-21,2019.

33. COSSEAU, C. et al. The commensal Streptococcus salivarius K12 downregulates the innate immune responses of human epithelial cells and promotes hostmicrobe homeostasis. Infection and Immunity, n.76, n.9,p.4163-4175,2008.

34. RIBBLE, C.S. et al. Effect of time of year, weather, and the pattern of auction market sales on fatal fibrinous pneumonia (shipping fever) in calves in a large feedlot in Alberta (1985-1988). Canadian Journal of Veterinary Research,v.59, n.3,p.167-172,1995.

35. RIBBLE, C.S. et al. The pattern of fatal fibrinous pneumonia (shipping fever) affecting calves in a large feedlot in Alberta (1985-1988). Canadian Journal of Veterinary Research,v.36, n.12,p.753-757,1995.

36. EDWARDS, A.J. Respiratory diseases of feedlot cattle in the central USA. Bovine Practitioner, n.30, p.5-7,1996.

37. GAGEA, M.I. et al. Diseases and pathogens associated with mortality in Ontario beef feedlots. Journal of Veterinary Diagnostic,v.18, n.1,p.18-28,2006. 
38. AUBRY, P. et al. Health and performance of young dairy calves vaccinated with a modified-live Mannheimia haemolytica and Pasteurella multocida vaccine. Journal of the American Veterinary Medical Association, v.219, n.12, p.1739-1742,2001.

39. LOVE, W.J. et al. Development of a novel clinical scoring system for on-farm diagnosis of bovine respiratory disease in pre-weaned dairy calves. PeerJ, v. 2, n.1,p.e238,2014.

40. AMRINE, D.E. et al. Pulmonary lesions and clinical disease response to Mannheimia haemolytica challenge 10 days following administration of tildipirosin or tulathromycin. Journal of Animal Science, v.92, p.311-319,2014.

41. NICKELL, J.S.; WHITE, B.J. Metaphylactic antimicrobial therapy for bovine respiratory disease in stocker and feedlot cattle. Veterinary Clinics of North America: Food Animal Practice, v.26, n.2, p.285-301, 2010.

42. WILKINS, P.A. et al. Doenças do sistema respiratório. In: SMITH, B.P. (Ed.) Medicina Interna de Grandes Animais. São Paulo: Manole, 2006. p.479592.

43. ASSIS-BRASIL, N.D. et al. Enfermidades diagnosticadas em bezerros na região sul do Rio Grande do Sul.Pesquisa Veterinária Brasileira,v.33, n.4,p.423-430, 2013.

44. ASSIS-BRASIL, N.D. et al. Doenças respiratórias em bezerros na região sul do Rio Grande do Sul: estudo de 33 surtos. Pesquisa Veterinária Brasileira, v.33, n.6,p.745-751,2013.

45. THEURER, M.E. et al. A stochastic model to determine the economic value of changing diagnostic test characteristics for identification of cattle for treatment of bovine respiratory disease. Journal of Animal Science,v.93,n.3,p.1398-1410,2015.

46. COOPER, V.L.; BRODERSEN, B.W. Respiratory disease diagnostics of cattle. Veterinary Clinics of North America: Food Animal Practice, v.26, n.2, p.409416,2010.

47. FULTON, R.W. et al. Lung pathology and infectious agents in fatal feddlot pneumonias and relationship with mortality, disease onset, and treatments. Journal of Veterinary Diagnostic Investigation, v.21, n.4, p.464-477,2009.

48. COCKCROFT, P.D. Bovine Respiratory Disease (BRD): diagnosis, prevention and control bovine medicine.In: COCKCROFT,P.D.(Ed.). Bovine Medicine. Nova Jersey: John Wiley \& Sons, Ltd., 2015. p.543548.

49.JONES,M.L.; ALLISON, R.W. Evaluation of the ruminant complete blood cell count. Veterinary Clinics of North America: Food Animal Practice, v.23, n.3, p.377402,2007.

50. AICH, P. et al. Biomarkers for prediction of bovine respiratory disease outcome. OMICS, v.13, n.3, p.199209,2009.

51. THEURER, M.E. et al. Effect of Mannheimia baemolytica pneumonia on behavior and physiologic responses of calves during high ambient environmental temperatures. Journal of Animal Science, v.91, n.8, p.3917-3929,2013.

52. IDOATE, I. et al. Acute phase proteins in naturally occurring respiratory disease of feedlot cattle. Veterinary Immunology and Immunopathology, n.163, n.3-4, p.221-226,2015. 
53. PRINGLE, J.K. et al. Bronchoalveolar lavage of cranial and caudal lung regions in selected normal calves: Cellular, microbiological, immunoglobulin, serological and histological variables. Canadian Journal of Veterinary Research, v.52, n.2, p.239-248,1988.

54. GONÇALVES, R.C. et al. Lavagem traqueobrônquica por sondagem nasotraqueal em bezerros. Arquivo Brasileiro de Medicina Veterinária e Zootecnia, v.56, n.3,p.307-311,2004.

55. ALLEN, J.W. et al. Cytological findings in bronchoalveolar lavage fluid from feedlot calves: Associations with pulmonary microbial flora. Canadian Journal of Veterinary Research, v.56, n.2, p.122-126, 1992.

56. FULTON, R.W. et al. Bovine coronavirus (BCV) infections in transported commingled beef cattle and sole-source ranch calves. Canadian Journal of Veterinary Research,v.75, n.3,p.191-199,2011.

57. ISHIZAKI, H. et al. Influence of trucktransportation on the function of bronchoalveolar lavage fluid cells in cattle. Veterinary Immunology and Immunopathology, v.105, n.1-2,p.67-74,2005.

58. BRAUN, U. et al. Ultrasonographic findings in cattle with pleuropneumonia. Veterinary Record, v.141, n.1,p.12-17,1997.

59. BABKINE, M.; BLOND, L. Ultrasonography of the bovine respiratory system and its practical application. Veterinary Clinics of North America: Food Animal Practice,v.25, n.3, p.633-649, 2009.

60. BRAUN, U. et al. Überblick über die ultraschalluntersuchung der lunge beim kalb. Schweiz Arch Tierheilkd, v.162,n.9, p.513-530,2020.
61. OLLIVETT, T.L. Understanding the diagnosis and risk factors for respiratory disease in dairy calves. 2014. 153f. (Tese Phd) - University of Guelph, Ontário, Canadá.

62. OLLIVETT, T.L. et al. Thoracic ultrasonography and bronchoalveolar lavage fluid analysis in holstein calves with subclinical lung lesions. Journal of Veterinary Internal Medicine, v.29, n.6,p.1728-1734,2015.

63. BUCZINSKI, S. et al. Inter-rater agrément and reliability of thoracic ultrasonographic findings in feedlot calves, with or without naturally occurring bronchopneumonia. Journal of Veterinary Internal Medicine, v.32, n.5, p.1787-1792, 2018.

64. BUCZINSKI, S. et al. Comparison of thoracic auscultation, clinical score, and ultrasonography as indicators of bovine respiratory disease in preweaned dairy calves. Journal of Veterinary Internal Medicine, v.28,n.1,p.234-342,2014.

65. BURGESS, B.A. et al. The development of a percutaneous lung biopsy procedure for use on feedlot steers. Canadian Journal of Veterinary Research, v.75, n.4,p.254-260,2011.

66. BURGESS, B.A. et al. The use of lung biopsy to determine early lung pathology and its association with health and production outcomes in feedlot steers. Canadian Journal of Veterinary Research, v.77, n.4, p.281-287,2013.

67.ABUTARBUSH, S.M. et al. Evaluation of the diagnostic and prognostic utility of ultrasonography at first diagnosis of presumptive bovine respiratory disease. Canadian Journal of Veterinary Research, v.76, n.1, p.2332,2012.

68. BERMAN, J. et al. Bayesian estimation of sensitiv- 
ity and specificity of systematic thoracic ultrasound exam for diagnosis of bovine respiratory disease in preweaned calves. Preventive Veterinary Medicine, v.162, n.1,p.38-45,2019.

69. RADEMACHER, R.D. et al. Systematic thoracic ultrasonography in acute bovine respiratory disease of feedlot steers: impact of lung consolidation on diagnosis and prognosis in a case-control study. Bovine Practitioner,v.48, p.1-10,2014.

70. FLÖCK, M. Diagnostic ultrasonography in cattle with thoracic disease. Veterinary Journal, v.167, n.3, p.272-280,2004.

71. THARWAT, M.; OIKAWA, S. Ultrasonographic evaluation of cattle and buffaloes with respiratory disorders. Tropical Animal Health and Production, v.43, n.4,p.803-810,2011.

72. OLLIVETT, T.L.; BUCZINSKI, S. On-farm use of ultrasonography for bovine respiratory disease. Veterinary Clinics of North America: Food Animal Practice, v.32,n.1,p.19-35,2016.

73. SCOTT, P. Ultrasonographic findings in adult cattle with chronic suppurative pneumonia. In Practice, v.35, n.8,p.460-469, 2013.

\section{ADAMS,E.A.; BUCZINSKI, S. Short communi-} cation: ultrasonographic assessment of lung consolidation postweaning and survival to the first lactation in dairy heifers. Journal of Dairy Science, v.99, n.2, p.1465$1470,2016$.

75. RABELING, B. et al.Ultrasonographic findings in calves with respiratory disease. Veterinary Record,v.143, n.17,p.468-471,1998.

76. BLOND, L.; BUCZINSKI, S. Basis of ultrasound imaging and the main artifacts in bovine medicine. Veterinary Clinics of North America: Food Animal Practice, v.25, n.3, p.553-565,2009.

77. STREETER, R.N.; STEP, D.L. Diagnostic ultrasonography in ruminants. Veterinary Clinics of North America: Food Animal Practice, v.23, n.3, p.541$574,2007$.

78. SCOTT, P.R. The role of ultrasonography as an adjunct to clinical examination in sheep practice. Irish Veterinary Journal, v.61, n.7,p.474-480, 2008.

79. JUNG, C.; BOSTEDT, H. Thoracic ultrasonography technique in newborn calves and description of normal and pathological findings. Veterinary Radiology Eo Ultrasound, v.45, n.4, p.331-335, 2004.

80. DEXHEIMER NETO, F.L. et al. Ultrassom pulmonar em pacientes críticos: uma nova ferramenta diagnóstica. Jornal Brasileiro de Pneumologia, v.38, n.2, p.246-256,2012.

81. WITTUM, T.E. et al. Relationships among treatment for respiratory tract disease, pulmonary lesions evident at slaughter, and rate of weight gain in feedlot cattle. Journal of the American Veterinary Medical Association,v.209, n.4,p.814-818, 1996.

82. GARDNER, B.A. et al. Health of finishing steers: effects on performance, carcass traits, and meat tenderness. Journal of Animal Science, v.77, n.12, p.3168-3175, 1999.

83. CASWELL, J.F.; WILLIAMS, K.J. Respiratory System. In: MAXIE, M.G. (Ed). Pathology of Domestic Animals. Philadelphia: Saunders Elsevier, 2007.p.523-655.

84. LÓPEZ, A. Sistema Respiratório. In: MCGAVIN, 
M.D.; ZACHARY, J.F. (Ed). Bases da Patologia em Veterinária. Rio de Janeiro: Elsevier,2009.p.463-558.

85. SANTOS, R.L.; GUEDES, R.M.C. Sistema Respiratório. In: SANTOS, R.L.; ALESSI, A.C. (Ed). Patologia Veterinária.São Paulo: Roca;2016.p.1-48.

86. PANCIERA, R.J.; CONFER, A.W. Pathogenesis and pathology of bovine pneumonia. Veterinary Clinics of North America: Food Animal Practice, v.26, n.2, p.191$214,2010$.

87. HODGINS, D.C.; SHEWEN, P.E. Pasteurella and Mannheimia spp. infections. In: COETZER, J.A.W; TUSTIN, R.C. (Ed). Infectious Disease of Livestock. Oxford: Oxford University Press, 2004. p.1672-1676.

88. DEDONDER, K.D.; APLEY, M.D. A literature review of antimicrobial resistance in pathogens associated with bovine respiratory disease. Animal Health Research Reviews,v.16.n.2,p.125-134,2015.

89. WATTS, J.L.; SWEENEY, M.T. Antimicrobial resistance in bovine respiratory disease pathogens: measures, trends, and impact on efficacy. Veterinary Clinics of North America: Food Animal Practice, v.26, n.1, p.79-88,2010.

90. BOOKER, C.W.; LUBBERS, B.V. Bovine respiratory disease treatment failure impact and potential causes. Veterinary Clinics of North America: Food Animal Practice, v.36,n.2,p.487-496,2020.

91. TAYLOR, J.D. et al. The epidemiology of bovine respiratory disease: what is the evidence for preventive measures. Canadian Veterinary Journal, v.51, n.12, p.1351-1359,2010.

92. YOUNG, C. Antimicrobial metaphylaxis for undifferentiated bovine respiratory disease. Compendium on Continuing Education for the Practising Veterinarian,v.17,p.133-142,1995.

93. GRIFFIN, D. Antibiotic metaphylaxis to control respiratory disease. Cattle Industry Annual Convention and Trade Show.2007.606p.

94. URBAN-CHMIEL, R.; GROOM, R.D.L. Prevention and control of bovine respiratory disease. Livestock Science, v.3,p.27-36,2012.

95. MAGALHÃES, L.Q. et al. Use of metaphylactic protocols based on the risk to develop bovine respiratory diseases in feedlot cattle. Ciência Rural, v.47, n.8, p.1-6,2017.

96. BARBOSA, I.L.A. et al. Ganho de peso em bovinos em confinamento utilizando enrofloxacino e polivacinas. Pubvet,v.5, n.8,p.1043-1049,2011.

97. O'CONNOR, A.M. et al. A systematic review and network meta-analysis of injectable antibiotic options for the control of bovine respiratory disease in the first 45 days post arrival at the feedlot. Animal Health Research Revierws,v.20,n.2,p.163-181,2019.

98. WHO - World Health Organization global principles for the containment of antimicrobial resistance in animals intended for food. Geneva: World Health Organization, 2000.23p.

99. FAO/WHO - Second joint FAO/OIE/WHO expert workshop on non-human antimicrobial usage and antimicrobial resistance: management options. Geneva:World Health Organization, 2004.31p.

100. ROTH,J.A. Veterinary vaccines and their importance to animal health and public health. Procedia in Vaccinology,v.5,p.127-136,2011. 
101. RIDPATH, J. Immunology of BVDV vaccines. Biologicals, v.41,n.1,p.14-19,2013.

102. GOMES, R.C. Influência etária na resposta imunológica de bezerros à vacinação intranasal. 2016. 145f. Tese (Doutorado em Ciências) - Faculdade de Medicina Veterinária e Zootecnia, Universidade de São Paulo, São Paulo, São Paulo.

103. OLLIVET, T.L. et al. Field trial to evaluate the effect of an intranasal respiratory vaccine protocol on calf health, ultrasonographic lung consolidation, and growth in Holstein dairy calves. Journal of Dairy Science, v.101, n.9,p.1-10.2017.

104. SCHUMAHER, T.F. et al. Effects of vaccination timing against respiratory pathogens on performance, antibody response, and health in feedlot cattle. Journal of Animal Science, v.97, n.2, p.620-630,2019.

105. SERAFINI, M.F. Estudo do complexo de doenças respiratórias dos bovinos em confinamento de terminação: fatores de risco, aspectos clínicos e anatomopatológicos. 2016. 45f. Dissertação (Mestrado em Ciência Animal) - Universidade Federal de Minas Gerais, Belo Horizonte, Minas Gerais. 